\title{
Determination of Some Heavy Metals in Real Samples by FAAS after Preconcentration on 4-Nitro-2-(2-nitro- phenelazo)phenol Modified Activated Carbon
}

\author{
AMIR H. M. SARRAFI ${ }^{\mathrm{a}^{*}}$, ELAHE KONOZ ${ }^{\mathrm{a}}$ and AZADEH KHANMOHAMMADI ${ }^{\mathrm{b}}$

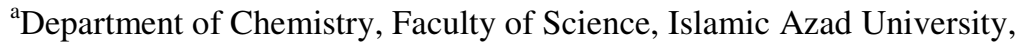 \\ Central Tehran Branch, Tehran, Iran \\ ${ }^{\mathrm{a}, \mathrm{b}}$ Department of Chemistry, Faculty of Engineering, Islamic Azad University, \\ Gachsaran Branch, Gachsaran, Iran \\ a_mohsensarafi@iauctb.ac.ir
}

Received 13 May 2012 / Accepted 30 May 2012

\begin{abstract}
A sensitive and simple method for determination of some heavy metals by flame atomic spectrometry after simultaneous preconcentration of trace heavy metals ions in some cereal and vegetable samples has been reported. The method is based on the adsorption of $\mathrm{Cu}^{2+}, \mathrm{Fe}^{2+}, \mathrm{Zn}^{2+}$ and $\mathrm{Pb}^{2+}$ on 4-nitro-2-(2-nitro-phenelazo)phenol (NNPP) loaded on activated carbon (AC). The adsorbed

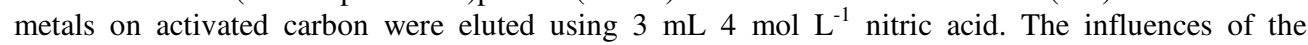
analytical parameters including $\mathrm{pH}$, flow rate of sample and eluent, type and concentration of eluent, amount of adsorbent and sample volume were investigated. The recoveries of analytes were generally higher than $95 \%$.
\end{abstract}

Keywords: FAAS, Heavy metals, Solid phase extraction, Activated carbon, 4-Nitro-2-(2-nitrophenelazo)phenol.

\section{Introduction}

For designating the level of pollution as the rise in ecological and health problems, required to determination of trace metals in environmental samples ${ }^{1-3}$. These samples have complex matrices therefore direct analysis of these samples is difficult $^{3-6}$ and because of low concentration of heavy metals, preconcentration is suggested to solve the above problems.

The advantages of solid phase extraction (SPE) as a preconcentration method are counted as fast, simple and direct application in micro liter volume without any sample loss, higher preconcentration factor, rapid phase separation, time and cost saving ${ }^{7-10}$. The basic principle of SPE is the transfer of analytes from aqueous phase to the active sites of solid phase. A number of supports and chelating ligands have been widely used for the preconcentration and separation of trace metal ions from various matrices ${ }^{11-19}$. 
Activated carbon (AC) has the ability to absorb both organic and inorganic compounds. Therefore it is widely used for many purposes both in laboratorial and industrial settings. Application of modified AC as supports for SPE has increased enrichment factor for trace metals in different matrices. The separation of metal ions on AC can be improved in presence of chelating agent ${ }^{8-10}$.

The purpose of this work is to investigate a preconcentration separation procedure for $\mathrm{Cu}^{2+}, \mathrm{Fe}^{2+}, \mathrm{Zn}^{2+}$ and $\mathrm{Pb}^{2+}$ in some cereal and vegetable materials on activated carbon modified with 4-nitro-2-(2-nitro-phenelazo) phenol (NNPP).

\section{Experimental}

The measurement of metal ions were performed with a Shimadzu 680AA atomic absorption spectrometer equipped with a hollow cathode lamp and a deuterium background correct, at respective wavelengths using air-acetylene flame. The instrumental parameters were those recommended by manufacturer. A Metrohm $691 \mathrm{pH} /$ ion meter with a combined glasscalomel electrode was used for adjustment of test solution $\mathrm{pH}$.

\section{Reagents}

Acid and bases were of the highest purity available from Merck and were used as received. Doubly distilled deionized water was used throughout. The analytical reagent grade nitrate salts of lead, copper, zinc and iron (Merck, Darmstadt, Germany) were used without any further purification. The $\mathrm{pH}$ adjustment was done by the addition of dilute nitric acid or sodium hydroxide to phosphate solution for preparing the desired $\mathrm{pH}$ buffer solution. Activated carbon (AC) [gas chromatographic grade, 40-60 mesh from Merck] was cleaned in hydrochloric acid for 2 days. Then it was washed with water and dried at $110^{\circ} \mathrm{C}$ for 1 day. The 4-nitro-2-(2-nitro-phenelazo) phenol (NNPP) was prepared according to the literature ${ }^{20}$.

\section{Preparation of NNPP-coated activated carbon}

A pyrex glass column containing $0.4 \mathrm{~g}$ of activated carbon in water suspension was $10 \mathrm{~cm}$ long and $1 \mathrm{~cm}$ in internal diameter. The bed height in the column was approximately $1 \mathrm{~cm}$. The AC (400 mg) was impregnated with NNPP solution through the column packed with

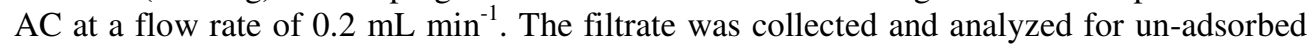
with the UV-Vis spectrophotometer at maximum wavelength. The column was then washed twice with $5 \mathrm{~mL}$ water and the filtrates were analyzed for that was released. The optimum amount of NNPP on AC column was $10 \mathrm{mg}$.

\section{Preconcentration procedure}

The $\mathrm{pH}$ of the solution was adjusted to 4.5 with buffer and passed through the NNPP-loaded AC column at a flow rate of $3 \mathrm{~mL} \mathrm{~min}^{-1}$ with the aid of a suction pump. The analyte was then eluted $3 \mathrm{~mL}$ of $4.0 \mathrm{~mol} \mathrm{~L}^{-1} \mathrm{HNO}_{3}$. The metal ions content of the eluent was measured by FAAS.

\section{Pretreatment of real samples}

Accurately weighed amounts of dried and crushing vegetables and cereals in small mesh were heated in silica crucible for $3 \mathrm{~h}$ on a hot plate and the charred material was transferred to furnace for overnight heating at $650{ }^{\circ} \mathrm{C}$. The residue was cooled, gain kept in furnace for $2 \mathrm{~h}$ at the same temperature, to decompose organic matter completely. The final residue was treated with $3 \mathrm{~mL}$ concentrated hydrochloric acid and $2-4 \mathrm{~mL} 70 \%$ perchloric acid evaporated to fumes, so that all the metals change to respective ions. The solid residue was dissolved in water, filtered and by keeping the $\mathrm{pH}$ at 4.5 made up to $250 \mathrm{~mL}$ by addition of diluted $\mathrm{HNO}_{3}$ solution ${ }^{21}$. 


\section{Results and Discussion}

In preliminary experiments, it was observed that preconcentration of the metals with the untreated $\mathrm{AC}$ is not suitable for $\mathrm{Cu}, \mathrm{Fe}, \mathrm{Zn}$ and $\mathrm{Pb}$. Therefore, NNPP-AC seems to be a better sorbent in simultaneous sorption of the studied elements. Due to the existence of a donating atoms as $\mathrm{N}$ and $\mathrm{O}\left(\mathrm{OH}\right.$ and $\left.\mathrm{NO}_{2}\right)$ group in NNPP was expected to increase both the stability and selectivity of its complex toward ions.

\section{Effect of $\mathrm{pH}$}

In the solid phase extraction studies, $\mathrm{pH}$ of the working solution is main factor for the quantitative adsorption of analytes on solid phase. In order to optimize the sorption conditions for the retention of the ions on modified $\mathrm{AC}$, the effects of $\mathrm{pH}$ was investigated in the $\mathrm{pH}$ rang of 3-9 by using column packed with $0.4 \mathrm{~g}$ modified AC. Figure 1 shows that the optimal $\mathrm{pH}$ value in 4.5 . Considering these results, the $\mathrm{pH}=4.5$ has been recommended for subsequent experiments.

\section{Effect of the amount of activated carbon}

In the adsorption step, an appropriate amount of activated carbon should be used in order to obtain quantitative retention of metals. On the hand, an excess amount of the sorbent also prevents the quantitative elution of the retained metals by small volume of eluent. The influences of the amounts of activated carbon filled to the column were also investigated. The results are given in Figure 2. The recoveries of analytes were increased with amount of $\mathrm{AC}$ and reach to quantitative value of $0.4 \mathrm{~g}$ of activated carbon.

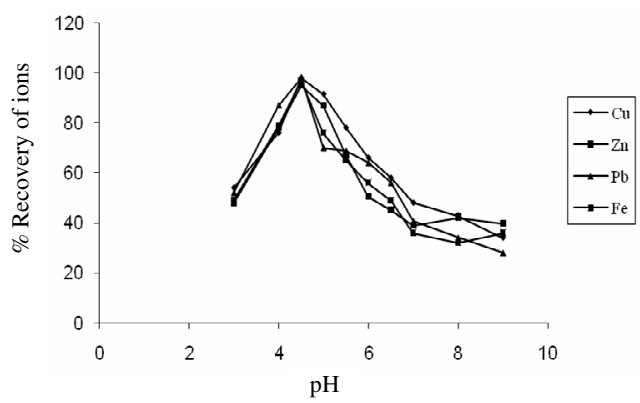

Figure 1. Effect of $\mathrm{pH}$ on recovery of metal ions $(\mathrm{n}=3)$

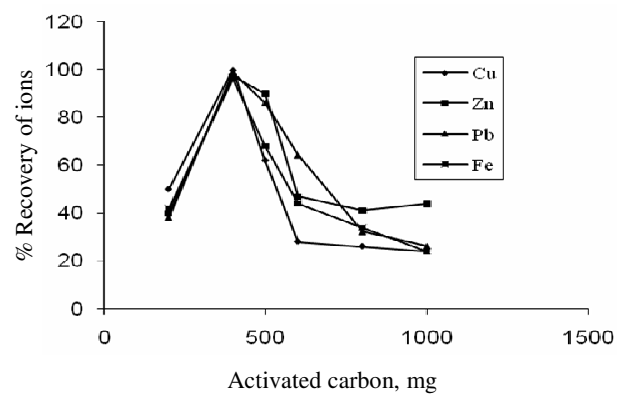

Figure 2. Effect of amount of activated carbon on recovery of metal ions $(n=3)$

\section{Effect of the NNPP amounts}

The effects of the ligand amount on the retention of the analyte ions on NNPP-AC were also examined. The results are depicted Figure 3. The recoveries analytes were quantitative, till the addition of $20 \mathrm{mg}$ ligand. After that, the recovery values decreased, probably due to the formation of charged complex which could not been completely retained on solid phase.

\section{Type and volume of the eluent}

The nature and concentration of agents were found to have a significant effect on the elution process of the retained ions from the solid phase. As could be seen from Figure 1, the uptake of these metal ions was negligible at $\mathrm{pH}<4$; therefore the acidic eluents are the best solution for extraction of adsorbed ions. Different eluting solutions were used for elution of ions, which retained on NNPP-AC. The effect of eluent volumes and concentration on the recoveries 
of the analytes were also investigated .Quantitative recoveries of $\mathrm{Cu}^{2+}, \mathrm{Fe}^{2+}, \mathrm{Zn}^{2+}$ and $\mathrm{Pb}^{2+}$ ions were obtained with $3 \mathrm{~mL}$ of $4 \mathrm{~mol} \mathrm{~L}^{-1} \mathrm{HNO}_{3}$ as compared to other eluents. Therefore, $3 \mathrm{~mL}$ of $4 \mathrm{~mol} \mathrm{~L}^{-1} \mathrm{HNO}_{3}$ was used in the subsequent experiments.

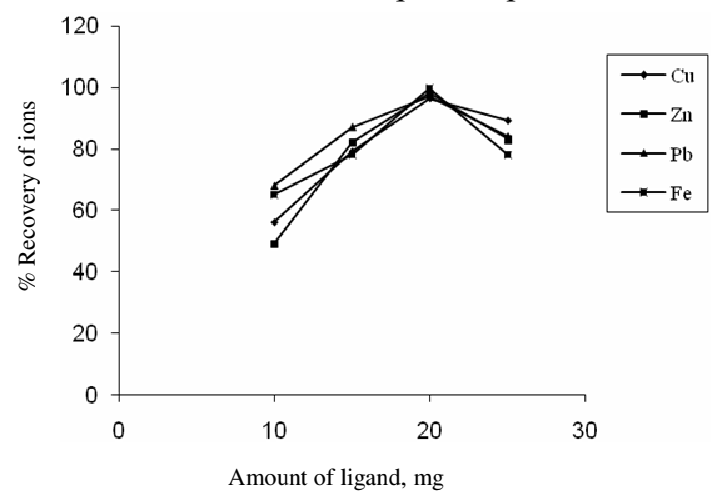

Figure 3. Effect of amount of ligand loaded on recovery of metal ions $(n=3)$

\section{Flow rates}

The effects of the sample and eluent flow rates on the retentions and recoveries of analyte ions on the adsorbent were also examined in the flow rate range of $1-12 \mathrm{~mL} \mathrm{~min}^{-1}$ under optimal conditions with model solutions containing analyte elements. All the analyte ions were quantitatively retained and recovered in the sample and eluent flow rate of 1-3 $\mathrm{mL} \mathrm{min}^{-1}$. After $3 \mathrm{~mL} \mathrm{~min}^{-1}$, the recoveries were not quantitative due to insufficient contact between analytes adsorbent. In the all-further works, $3 \mathrm{~mL} \mathrm{~min}^{-1}$ was selected as sample and eluent flow rate.

\section{Sample volume}

The effect of the sample solution volume on the metal sorption was studied by passing $100-200 \mathrm{~mL}$ volumes through the column at a $3 \mathrm{~mL} \mathrm{~min}^{-1}$ flow rate. The adsorption of the metal ions was not affected by sample volume below $1500 \mathrm{~mL}$. Above this volume of sample solution, the percent sorption decreased for the analytes. The recoveries of analytes decrease probably due to the excess analytes loaded over the column capacity with increasing sample volume above $1500 \mathrm{~mL}$. In the present study $1650 \mathrm{~mL}$ of sample solution was adopted for the preconcentration of the investigated ions, the adsorbed metals can be eluted with $3 \mathrm{~mL}$ of $4 \mathrm{~mol} \mathrm{~L}^{-1} \mathrm{HNO}_{3}$ and a preconcentration factor of 550 is achieved.

\section{Interferences}

In order to assess the possible analytical applications of the preconcentration procedure presented, the effect of some foreign ions which interfere with the determination of trace of these ions or/and often accompany analyte ions in various real environmental samples was examined with the optimized conditions. The results are summarized in Table 1. The tolerance limit is defined as the ion concentration causing a relative error smaller than $\pm 5 \%$ related to the preconcentration and determination of analytes. The tolerable levels of the some heavy metals ions are suitable for the separation and preconcentration of ions in the real samples examined present study, because the levels of transition metals in these samples are lower than their interfere level. It can be seen that the major matrix ions in the real samples show no obvious interference with the preconcentration of the mentioned ions. 
Table 1. Effect of the matrix ions on the recoveries of the examined metals ion $(n=3)$

\begin{tabular}{cc}
\hline Ion & Tolerance limit ion, $\mathrm{mgL}^{-1}$ \\
\hline $\mathrm{Na}^{+}, \mathrm{K}^{+}, \mathrm{Li}^{+}, \mathrm{Ca}^{2+}, \mathrm{Mg}^{2+}$ & 1000 \\
$\mathrm{I}^{-}, \mathrm{Br}^{-}$ & 750 \\
$\mathrm{Cr}^{3+}, \mathrm{Cd}^{2+}, \mathrm{SO}_{4}{ }^{2-}$ & 600 \\
$\mathrm{HCO}_{3}^{-}, \mathrm{CO}_{3}^{2-}$ & 800 \\
$\mathrm{Ni}^{2+}, \mathrm{Co}^{2+}, \mathrm{Mn}^{2+}$ & 650 \\
$\mathrm{SCN}^{-}$ & 450 \\
$\mathrm{Ag}^{+}$ & 550 \\
\hline
\end{tabular}

\section{Analytical performance}

By passing $100 \mathrm{~mL}$ solution of $0.5-10 \mu \mathrm{gL}^{-1}$ of all ions understudy, the calibration cures, repeatability and reproducibility were obtained. The effluent was sent to FAAS for evaluating ions content. The sensitivity of developed method was reproduced by detecting the limit of detection (LOD), defined as the lowest concentration of metal ions below which quantitative sorption of the metal by basic alumina is not perceptibly seen. The limit of detection (LOD) of the present work was calculated under optimal experimental conditions after application of the preconcentration procedure to blank solutions (without samples or standards). The limit of detections based on three times the standard deviations of the blank $\left(N=6, L O D=X_{b}+3 s\right.$, where LOD is the limit of detection and $\mathrm{X}_{\mathrm{b}}$ is the blank value) for $\mathrm{Cu}^{2+}, \mathrm{Fe}^{2+}, \mathrm{Zn}^{2+}$ and $\mathrm{Pb}^{2+}$ were found to be $0.17,0.16,0.11$ and $0.12 \mu \mathrm{gL}^{-1}$, respectively ${ }^{22}$. The characteristic performances of the method which presented in Table 2 show good linear range, low detection limits, high reproducibility and low relative standard deviation for all elements.

Table 2. Specification of presented method at optimum conditions each element $(n=3)$

\begin{tabular}{ccccc}
\hline Parameters & $\mathrm{Cu}$ & $\mathrm{Pb}$ & $\mathrm{Zn}$ & $\mathrm{Fe}$ \\
\hline Linear range, $\mu \mathrm{g} \mathrm{L}^{-1}$ & $0.0005-0.09$ & $0.001-0.09$ & $0.0005-0.01$ & $0.001-0.09$ \\
Detection limit, $\mathrm{ng} \mathrm{mL}^{-1}$ & 0.17 & 0.12 & 0.11 & 0.16 \\
R.S.D. \% & 1.2 & 1.3 & 1.5 & 1.7 \\
Recovery \% & 96.4 & 97.8 & 98.4 & 99.2 \\
\hline
\end{tabular}

\section{Applications to real samples}

In order to assess the applicability of the method to real samples, with different matrices containing varying amounts of a variety of diverse ions, it was applied to the separation and recovery of ions from different matrices such as vegetables and cereals. Spiking experiments using standard addition method checked reliabilities. The percentage of recoveries and relative standard deviation for each element in spiked vegetable and water samples are given in Table 3-4. As seen, the results of three analyses of each sample show that, in all cases, the ions recoveries are almost quantitative with a low R.S.D.

Table 3. Recovery of trace elements from spiked cereal samples that irrigated with tap water and waste water after application of presented procedure. $(n=3)$

\begin{tabular}{|c|c|c|c|c|c|c|c|c|c|}
\hline \multicolumn{5}{|c|}{ Irrigated with tap water } & \multicolumn{5}{|c|}{ Irrigated with waste water } \\
\hline Ion & Added* $^{*}$ & Found* & $\mathrm{RSD} \%$ & $\operatorname{Rec} \%$ & Added ${ }^{*}$ & Found* & $\mathrm{RSD} \%$ & $\operatorname{Rec} \%$ & \\
\hline $\mathrm{Cu}$ & 0.000 & 0.117 & 1.8 & - & 0.000 & 0.445 & 1.8 & - & \\
\hline & 0.050 & 0.165 & 2.1 & 97.0 & 0.050 & 0.493 & 2.1 & 96.0 & 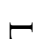 \\
\hline & 0.500 & 0.617 & 1.7 & 100.1 & 0.500 & 0.946 & 1.7 & 100.2 & 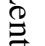 \\
\hline $\mathrm{Zn}$ & 0.000 & 0.06 & 1.7 & - & 0.000 & 0.216 & 1.7 & - & \\
\hline
\end{tabular}




\begin{tabular}{|c|c|c|c|c|c|c|c|c|c|}
\hline & 0.050 & 0.108 & 1.4 & 97.0 & 0.050 & 0.267 & 1.4 & 103.0 & \\
\hline & 0.500 & 0.559 & 1.7 & 99.0 & 0.500 & 0.767 & 1.8 & 99.0 & \\
\hline \multirow[t]{3}{*}{$\mathrm{Fe}$} & 0.000 & 0.925 & 1.8 & - & 0.000 & 1.425 & 1.7 & - & \\
\hline & 0.050 & 0.974 & 1.5 & 97.0 & 0.050 & 1474 & 1.4 & 99.0 & \\
\hline & 0.500 & 1.425 & 1.7 & 99.9 & 0.500 & 1.940 & 1.9 & 103.0 & \\
\hline \multirow[t]{3}{*}{$\mathrm{Pb}$} & 0.000 & 0.052 & 1.4 & - & 0.000 & 0.372 & 1.9 & - & \\
\hline & 0.050 & 0.101 & 1.7 & 103.0 & 0.050 & 0.421 & 2.1 & 98.0 & \\
\hline & 0.500 & 0.549 & 1.4 & 98 & 0.500 & 0.873 & 1.6 & 103.0 & \\
\hline \multirow[t]{3}{*}{$\mathrm{Cu}$} & 0.000 & 0.130 & 1.9 & - & 0.000 & 1.410 & 2.1 & - & \\
\hline & 0.050 & 0.182 & 1.4 & 104.0 & 0.050 & 1.462 & 1.4 & 104.0 & \\
\hline & 0.500 & 0.629 & 1.2 & 99.8 & 0.500 & 1.911 & 1.6 & 100.2 & \\
\hline \multirow[t]{3}{*}{$\mathrm{Zn}$} & 0.000 & 0.239 & 2.4 & - & 0.000 & 1.516 & 1.8 & - & \\
\hline & 0.050 & 0.290 & 2.1 & 102.0 & 0.050 & 1.561 & 1.2 & 103.0 & $\&$ \\
\hline & 0.500 & 0.739 & 2.3 & 100.0 & 0.500 & 2.010 & 1.7 & 100.4 & 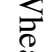 \\
\hline \multirow[t]{3}{*}{$\mathrm{Fe}$} & 0.000 & 1.742 & 1.3 & - & 0.000 & 4.566 & 1.4 & - & $\stackrel{\Rightarrow}{\circ}$ \\
\hline & 0.050 & 1.794 & 1.9 & 104.0 & 0.050 & 4.618 & 1.4 & 100.4 & \\
\hline & 0.500 & 2.240 & 1.7 & 101.0 & 0.500 & 5.060 & 2.5 & 99.9 & \\
\hline \multirow[t]{3}{*}{$\mathrm{Pb}$} & 0.000 & 0.239 & 2.4 & - & 0.000 & 1.010 & 1.8 & - & \\
\hline & 0.050 & 0.289 & 2.1 & 100.0 & 0.050 & 1.070 & 1.2 & 104.0 & \\
\hline & 0.500 & 0.739 & 1.8 & 100.1 & 0.500 & 1.520 & 2.1 & 100.3 & \\
\hline
\end{tabular}

Table 4. Recovery of trace elements from spiked vegetable samples that irrigated with tap water and waste water after application of presented procedure. $(\mathrm{n}=3)$

\begin{tabular}{|c|c|c|c|c|c|c|c|c|c|}
\hline \multicolumn{5}{|c|}{ Irrigated with tap water } & \multicolumn{4}{|c|}{ Irrigated with waste water } & \\
\hline Ion & Added* & Found ${ }^{*}$ & RSD\% & $\operatorname{Rec} \%$ & Added $^{*}$ & Found & RSD\% & Rec\% & \\
\hline \multirow[t]{3}{*}{$\mathrm{Cu}$} & 0.000 & 0.130 & 1.9 & - & 0.000 & 0.578 & 2.4 & - & \\
\hline & 0.050 & 0.182 & 1.4 & 103.0 & 0.050 & 0.629 & 2.1 & 103.0 & \\
\hline & 0.500 & 0.629 & 1.2 & 99.7 & 0.500 & 1.077 & 1.6 & 99.8 & \\
\hline \multirow[t]{3}{*}{$\mathrm{Zn}$} & 0.000 & 0.029 & 1.8 & - & 0.000 & 0.139 & 1.6 & - & 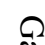 \\
\hline & 0.050 & 0.076 & 1.3 & 95.0 & 0.050 & 0.190 & 1.3 & 103.0 & \\
\hline & 0.500 & 0.527 & 2.1 & 99.6 & 0.500 & 0.641 & 1.5 & 100.4 & $\frac{D}{2}$ \\
\hline \multirow[t]{3}{*}{$\mathrm{Fe}$} & 0.000 & 1.441 & 1.8 & - & 0.000 & 2.186 & 2.1 & - & 要 \\
\hline & 0.050 & 1.493 & 1.4 & 104.0 & 0.050 & 2.238 & 1.5 & 105.0 & $\infty$ \\
\hline & 0.500 & 1.939 & 1.4 & 99.7 & 0.500 & 2.687 & 2.1 & 100.3 & \\
\hline \multirow[t]{3}{*}{$\mathrm{Pb}$} & 0.000 & 0.059 & 1.2 & - & 0.000 & 0.333 & 1.7 & - & \\
\hline & 0.050 & 0.099 & 2.3 & 96.0 & 0.050 & 0.385 & 1.3 & 103.0 & \\
\hline & 0.500 & 0.553 & 1.7 & 100.5 & 0.500 & 0.831 & 1.6 & 99.5 & \\
\hline \multirow[t]{3}{*}{$\mathrm{Cu}$} & 0.000 & 0.161 & 1.2 & - & 0.000 & 0.790 & 1.9 & - & \\
\hline & 0.050 & 0.213 & 1.5 & 104.0 & 0.050 & 0.838 & 1.6 & 96.0 & \\
\hline & 0.500 & 0.662 & 2.3 & 100.2 & 0.500 & 1.292 & 2.4 & 100.3 & $\pi$ \\
\hline \multirow[t]{3}{*}{$\mathrm{Zn}$} & 0.000 & 0.049 & 1.9 & - & 0.000 & 0.172 & 1.3 & - & \\
\hline & 0.050 & 0.097 & 1.2 & 97.0 & 0.050 & 0.220 & 1.9 & 96.0 & $\frac{5}{\sigma}$ \\
\hline & 0.500 & 0.551 & 2.4 & 100.5 & 0.500 & 0.674 & 1.4 & 100.0 & \\
\hline \multirow[t]{2}{*}{$\mathrm{Fe}$} & 0.000 & 0.576 & 1.8 & - & 0.000 & 0.972 & 1.3 & - & \\
\hline & 0.050 & 0.624 & 2.4 & 96.0 & 0.050 & 1.020 & 1.9 & 96.0 & \\
\hline
\end{tabular}




\begin{tabular}{|c|c|c|c|c|c|c|c|c|c|}
\hline \multirow{4}{*}{$\mathrm{Pb}$} & 0.500 & 1.075 & 1.5 & 99.7 & 0.500 & 1.471 & 2.0 & 99.8 & \\
\hline & 0.000 & 0.101 & 1.8 & - & 0.000 & 0.411 & 1.4 & - & \\
\hline & 0.050 & 0.152 & 1.9 & 102.0 & 0.050 & 0.460 & 1.5 & 97 & \\
\hline & 0.500 & 0.598 & 1.1 & 99.4 & 0.500 & 0.913 & 1.7 & 100.0 & \\
\hline \multirow[t]{3}{*}{$\mathrm{Cu}$} & 0.000 & 1.61 & 1.2 & - & 0.000 & 0.790 & 1.9 & - & \\
\hline & 0.050 & 0.213 & 1.5 & 104.0 & 0.050 & 0.838 & 1.6 & 96.0 & \\
\hline & 0.500 & 0.662 & 2.3 & 100.2 & 0.500 & 1.292 & 2.4 & 100.3 & \\
\hline \multirow[t]{3}{*}{$\mathrm{Zn}$} & 0.000 & 0.033 & 1.5 & - & 0.000 & 0.161 & 1.3 & - & \\
\hline & 0.050 & 0.082 & 1.7 & 98.0 & 0.050 & 0.212 & 1.9 & 102.0 & \\
\hline & 0.500 & 0.534 & 1.4 & 100.1 & 0.500 & 0.663 & 1.4 & 100.3 & . \\
\hline \multirow[t]{3}{*}{$\mathrm{Fe}$} & 0.000 & 0.161 & 1.8 & - & 0.000 & 0.972 & 1.3 & - & है \\
\hline & 0.050 & 0.212 & 2.2 & 102.0 & 0.050 & 1.020 & 1.9 & 96.0 & \\
\hline & 0.500 & 0.663 & 1.8 & 100.3 & 0.500 & 1.471 & 2.0 & 99.8 & \\
\hline \multirow[t]{3}{*}{$\mathrm{Pb}$} & 0.000 & 0.038 & 1.7 & - & 0.000 & 0.228 & 1.6 & - & \\
\hline & 0.050 & 0.089 & 1.6 & 103.0 & 0.050 & 0.727 & 1.9 & 99.8 & \\
\hline & 0.500 & 0.537 & 1.4 & 99.9 & 0.500 & 0.728 & 1.8 & 100.1 & \\
\hline
\end{tabular}

\section{Conclusion}

A new method was developed for the determination of trace metals. The procedure offers a useful multi-element preconcentration technique samples including vegetable and cereal samples with acceptable accuracy and precision. The other main advantages of the method include simplicity, time saving, no requirements of sophisticated instruments and cost effectiveness. Modified activated carbon on the column could be used all through the studies without any lost of its adsorption properties. The possibilities of using the extraction system in modified AC for the preconcentration and separation of the metallic cations in solution with relatively high contents of salts are extended.

\section{References}

1. Minczevski J, Chwastowska J and Dybezynski D, Separation and Preconcentration Methods in Inorganic Analysis, Ellis Horwood: Chichester, 1982.

2. Zih-Perenyi K, Jankovics P, Sugar E and Lasztity A, Spectrochim Acta, 2008, 63B(3), 445-449.

3. Somer G and Unlu A N, Turk J Chem., 2006, 30, 745-753.

4. Jalbani N, Kazi T G, Jamali M K, Arain M B, Afridi H I and Baloch A, J Food Comp Anal., 2007, 20(3-4), 226-231.

5. Arain M B, Kazi T G, Jamali M K, Jalbani N, Afridi H I and Baig J A, J Hazard Mater., 2008, 154(1-3), 998-1006.

6. Ansari R, Kazi T G, Jamali M K, Arain M B, Sherazi S T, Jalbani N and Afridi H I, $J$ AOAC Int., 2008, 91(2), 400-407.

7. Ghaedi M, Fathi M R, Shokrollahi A and Shajarat F, Anal Lett., 2006, 39, 1171-1185.

8. Soliman E M, Saleh M B and Ahmed S A, Anal Chim Acta, 2004, 523, 133-140.

9. Posta J, Alimonti A, Petruci F and Caroli S, Anal Chim Acta, 1996, 325, 185-193.

10. Chen J P and Lin M, Carbon, 2001, 39, 1491-1504.

11. Roy K and Lahiri S, Radiochim Acta, 2008, 96, 49-54.

12. Niskavaara H and Kontas E, Anal Chim Acta, 1990, 231, 273-282.

13. Pyrzynska K, Talanta, 1998, 47, 841-848. 
14. Tavakkoli L, Yamini Y, Ebrahimzadeh H, Nezhadali A, Shariati S and Noormohamadian F, J Hazard Mater., 2008, 152, 737-743.

15. Wu H, Jin Y, Tian Y, Tao X C and Bi S P, Atom Spectroscopy, 2007, 28(6), 220-226.

16. Fu R, Zeng H, Lu Y, Lai S Y, Chan W H and Ng C F, Carbon, 1995, 33(5), 657-661.

17. Hall P G, Gittins P M, Winn J M and Robertson J, Carbon, 1985, 23, 353-371.

18. Simpson N J K, Solid Phase Extraction-Principles. Techniques and Applications, Marcel Dekker: U.S.A., 2000.

19. Saygi K O, Tuzen M, Soylak M and Elci L, J Hazard Mater., 2008, 153(3), 1009-1014.

20. Liu G-B, Zhao H-Y, Yang H-J, Gao X, Li M-K and Thiemann T, Adv Synth Catal., 2007, 349(10), 1637-1640.

21. Ghaedi M, Ahmadi F and Soylak M, J Hazard Mater., 2007, 147(1-2), 226-231.

22. IUPAC, Nomenclature, Pure Appl Chem., 1976, 45, 105. 